\title{
HYBRID MANUFACTURING SYSTEM WITH THREE OPTIONS OF REMANUFACTURED AND DISPOSAL ITEMS
}

\author{
Ali Khaleel Dhaiban
}

Received February 16, 2018 / Accepted May 26, 2019

\begin{abstract}
This study is devoted to the optimal control of a hybrid manufacturing system with returned products after usage, represented as an infant mortality mode under a periodic review policy. Three hybrid models have been discussed; remanufacturing is continuous along the planning period (without a disposal option), remanufacturing happened in the second part of the planning period (disposal happen at arrival), and the remanufacturing rate was constrained by the demand rate (disposal of serviceable products to control inventory). Our contribution to literature was showed in two cases; usage the infant mortality mode to describe returned products, and simplified the optimal control model by using a different approach to achieve constraints. The explicit solution was realized using the Pontryagin maximum principle. Our numerical results suggest that the control of the inventory level satisfies the demands by combining rates of manufacturing and remanufacturing. Also, remanufacturing being continuous along the planning period is better as it minimizes the total cost.
\end{abstract}

Keywords: infant mortality mode, disposal items, Weibull distribution, optimal control, hybrid inventory system.

\section{INTRODUCTION}

Product quality plays a vital role in manufacturing planning. The higher quality of a product means only the manufacturing mode, while hybrid manufacturing mode results in low-quality products returned from customers. There is a certain proportion of products that will be defective in any stage of manufacturing. Defect happens due to factors such as material defects. In the last decade, economic and environmental development helped spread remanufacturing to many industries, such as electrical equipment and cellular phones (Gallo et al., 2009). Therefore, literature reported hybrid systems with different assumptions of the return rate and demand on the remanufactured product.

*Corresponding author - https://orcid.org/0000-0002-4383-828X

Apparatus of Supervision and Scientific Evaluation, Ministry of Higher Education and Scientific Research/Iraq, Dijlah University College, Baghdad, Iraq. https://en.duc.edu.iq/en

E-mails: ali_alzubiadi@yahoo.com / Khaleel.a@mohesr.gov.iq 
Many studies have dealt with a return rate as a random variable that adheres to probability distributions. Hsueh (2010), as well as Singh \& Saxena (2012), have used the normal distribution with product age and time function which had an effect on the expected value of the distribution. Also, using a normal distribution, Lalmazloumian et al. (2014) developed a hybrid model to determine the reorder point and product quantities coming from manufacturing and remanufacturing. Poisson distribution has been used to describe the return rate and demand by Nikoofal \& Moattar Husseini (2010) and Corum et al. (2014). The first discussed the effect of the reorder point on the optimal policy of the recovery system, while the second compared the models with and without remanufacturing based on costs of lead time, holding, and setup. A hybrid model with defective and deteriorated items to make a balance between manufacturing and remanufacturing rates that meet the demand has been developed by Dhaiban et al. (2018).

A deterministic return rate has been discussed in many studies. Konstantaras \& Papachristos (2007) studied a periodic review inventory with constant demand, a large amount of returned product at the beginning of the time period. They determined the switching time from remanufacturing to manufacturing. Single product, supplier, and retail have been addressed by Chung et al. (2008) and Liu et al. (2009). Chung et al. (2008) who assumed that remanufactured products satisfy the demand before the manufacturing process in the multi-echelon system. Liu et al. (2009) developed a model that included a single manufacturer, product, and retailer to determine the order quantity and retail pricing. The effect of incentive on the production rate, as well as a returned product not collected by the manufacturer in centralized and decentralized models was discussed by Kaya (2010). Turki et al. (2017) studied a hybrid system with infinite inventory and a maximum limit of the product rate for two machines. They aimed to minimize total cost by determining the optimal returned and optimal capacity of inventory, purchasing warehouse, and the vehicle. For more references to deterministic rate of return rate, the works of Guo \& Liang (2011), Reimann \& Zhang (2013), Raupp et al. (2015), Guo \& Ya (2015), Polotski et al. (2015), and Tahirov et al. (2016) can be reviewed.

Several researchers have used the Poisson process to describe the return rate of a product. Mahadevan et al. (2003) studied the system with a single product, and all returned product would be remanufactured. They also clarified the effect of lead time on the total cost that included holding and backorder costs. Jin et al. (2011) discussed the fact that the reassembly model with the returned product can be stocked with holding costs until demand requests. They considered the uncertainty of time and quality of supply and demand. Lim et al. (2011) used exponential distribution to describe the time of manufacturing and remanufacturing to minimize the total cost of the hybrid system. A single server for manufacturing and remanufacturing processes were discussed by Vercraene et al. (2014), with the rejection of some of the returned products, and Flapper et al. (2014), with acceptance of all of the returned products. Queuing model of the return product with a single product was discussed by Gayon et al. (2017). They assumed two options for disposing part of the returned products at arrival and serviceable to save inventory level without excess. For more references on the return rate, according to the Poisson process, 
the works of Kim et al. (2013), Tai \& Ching (2014), and Marshall \& Archibald (2015) can be reviewed.

Our model differed from the aforementioned studies in two cases. The first one, it uses the infant mortality mode to describe returned products. This mode is suitable for determining the return rate of the product, where its defects appear after use, such as electronic devices. Practically, this mode is better than other return rates that have been used in the previous studies because it has taken into account the time period of the used item to determine the return rate. Then, determining the amount of return carefully, which helped minimize the total cost by controlling the manufacturing and inventory. The second one, we simplified the optimal control model by using a different approach to achieve the constraint of manufacturing items that were sold as new products through rates of manufacturing and remanufacturing directly, instead, it considers a new constraint added to the optimal control model. Moreover, we discussed three options of disposal by developing three models of optimal control. These three models faced most of the practical situations. The first model without disposal, remanufacturing process was continuous over the planning period. The second model considered disposal that happened at arrival, the remanufacturing process that happens in the second part of the planning period. The last model discussed the disposal of serviceable products, a specific percent of remanufacturing product. The third disposal option that has been used in the case of secondary markets (Gayon et al., 2017). Table 1 shows our contribution compared other literature.

\section{MATERIALS AND METHODS}

\subsection{Notations and Assumptions Involved In the Model}

\subsubsection{Notations}

The following variables and parameters are used:

$T: \quad$ The length of the planning horizon $(T>0)$.

$I(t): \quad$ The inventory level at time $t$.

$P_{m}(t): \quad$ The manufacturing rate at time $t$.

$P_{r}(t): \quad$ The remanufacturing rate at time $t$.

$D(t)$ : Demand rate of the product at time $t$.

$\hat{I}(t): \quad$ The inventory goal level.

$\hat{P}_{m}(t)$ : The manufacturing goal rate.

$\hat{P}_{r}(t)$ : The remanufacturing goal rate.

$P_{d}(t): \quad$ The disposal rate at time $t$.

$\hat{P}_{d}(t): \quad$ The disposal goal rate.

$I(1): \quad$ The initial inventory level.

$R(t): \quad$ Return rate of the product at time $t$.

$c: \quad$ A penalty is incurred when the inventory level deviates from its goal level.

$k_{m}, k_{r}, k_{d}$ : A penalty is incurred when the total manufacturing, remanufacturing, disposal rate to deviate from its goal rate. 
Table 1 - Summary of literature review.

\begin{tabular}{|c|c|c|c|c|c|c|c|c|}
\hline Author(s) & 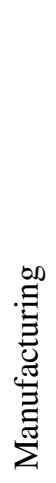 & 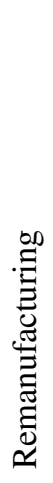 & 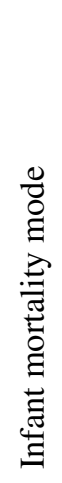 & 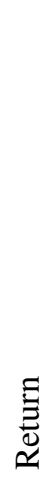 & 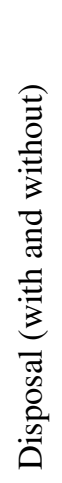 & 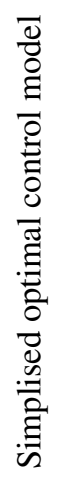 & 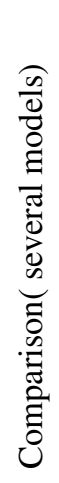 & 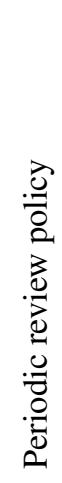 \\
\hline Mahadevan et al. (2003) & $\checkmark$ & $\checkmark$ & & $\checkmark$ & & & & $\checkmark$ \\
\hline Konstantaras \& Papachristos (2007) & $\checkmark$ & $\checkmark$ & & $\checkmark$ & & & $\checkmark$ & $\checkmark$ \\
\hline Chung et al. (2008) & $\checkmark$ & $\checkmark$ & & $\checkmark$ & & & & $\checkmark$ \\
\hline Liu et al. (2009) & $\checkmark$ & $\checkmark$ & & $\checkmark$ & & & & \\
\hline Hsueh (2010) & $\checkmark$ & $\checkmark$ & & $\checkmark$ & & & & \\
\hline Nikoofal \& Moattar Husseini (2010) & $\checkmark$ & $\checkmark$ & & $\checkmark$ & & & & $\checkmark$ \\
\hline Kaya (2010) & $\checkmark$ & $\checkmark$ & & $\checkmark$ & & & $\checkmark$ & \\
\hline Guo \& Liang (2011) & $\checkmark$ & $\checkmark$ & & $\checkmark$ & & & & \\
\hline Jin et al. (2011) & $\checkmark$ & $\checkmark$ & & $\checkmark$ & & & & $\checkmark$ \\
\hline Lim et al. (2011) & $\checkmark$ & $\checkmark$ & & $\checkmark$ & & & & \\
\hline Singh \& Saxena (2012) & $\checkmark$ & $\checkmark$ & & $\checkmark$ & & & & \\
\hline Kim et al. (2013) & $\checkmark$ & $\checkmark$ & & $\checkmark$ & $\checkmark$ & & $\checkmark$ & \\
\hline Reimann \& Zhang (2013) & $\checkmark$ & $\checkmark$ & & $\checkmark$ & & & & \\
\hline Lalmazloumian et al. (2014) & $\checkmark$ & $\checkmark$ & & $\checkmark$ & & & & $\checkmark$ \\
\hline Vercraene et al. (2014) & $\checkmark$ & $\checkmark$ & & $\checkmark$ & & & & \\
\hline Flapper et al. (2014) & $\checkmark$ & $\checkmark$ & & $\checkmark$ & & & & \\
\hline Corum et al. (2014) & $\checkmark$ & $\checkmark$ & & $\checkmark$ & & & $\checkmark$ & \\
\hline Tai \& Ching (2014) & $\checkmark$ & $\checkmark$ & & $\checkmark$ & & & & \\
\hline Marshall \& Archibald (2015) & $\checkmark$ & $\checkmark$ & & $\checkmark$ & & & $\checkmark$ & \\
\hline Raupp et al. (2015) & $\checkmark$ & $\checkmark$ & & $\checkmark$ & & & & \\
\hline Guo \& Ya (2015) & $\checkmark$ & $\checkmark$ & & $\checkmark$ & & & & \\
\hline Polotski et al. (2015) & $\checkmark$ & $\checkmark$ & & $\checkmark$ & & & & \\
\hline Tahirov et al. (2016) & $\checkmark$ & $\checkmark$ & & $\checkmark$ & & & $\checkmark$ & $\checkmark$ \\
\hline Gayon et al. (2017) & $\checkmark$ & $\checkmark$ & & $\checkmark$ & & & $\checkmark$ & \\
\hline Turki et al. (2017) & $\checkmark$ & $\checkmark$ & & $\checkmark$ & & & & $\checkmark$ \\
\hline Dhaiban et al. (2018) & $\checkmark$ & $\checkmark$ & & $\checkmark$ & & & & \\
\hline This article & $\checkmark$ & $\checkmark$ & $\checkmark$ & $\checkmark$ & $\checkmark$ & $\checkmark$ & $\checkmark$ & $\checkmark$ \\
\hline
\end{tabular}




\subsubsection{Assumptions}

We took into account the following points:

1. A firm can produce a single product, sell some, and stuck the rest in a warehouse.

2. The demand rate of a product is a fluctuating function of time and satisfied by both manufacturing and remanufacturing products.

3. Returned products are continuous, according to the infant mortality mode.

4. Neglect the lead time.

5. Three options for product disposal.

6. The firm has set an inventory goal level and goal rates of manufacturing and remanufacturing.

7. No shortages and unlimited storages.

\subsection{Infant Mortality Mode}

The infant mortality mode can be used to describe product failures due to defects such as materials and the machine age. The failure rate of the products, which appear after usage, will be highest in the first months, then decrease with time (Hartzell et al., 2011). The failure rate can be represented by a Hazard function of lifetime distributions. In this study, the returned rate of products, which represent returned products after use, is a Hazard function of the Weibull distribution (Kumar et al., 2012; Ross, 2010). The Hazard function of the Weibull distribution is:

$$
h(t)=\gamma t^{\gamma-1} ; \quad \gamma>0
$$

Now, the value of the Weibull parameter that is suitable with the infant mortality mode must be determined. The value of the Weibull parameter that is less than one leads to a curve of Hazard function similar to the infant mortality mode, which means that it decreases with time. Practically, the products with birth defects that appear after usage will be returned to the supplier from customers, and its amount will decrease over time. Figure 1 shows an example of the returned percentage of the product over time.

The returned items from the product of the third month can be expressed as follows:

$$
R(3)=0.08 D(1)+0.11 D(2)+0.2 D(3)
$$

The returned items represent a part of a product that satisfies the demand over three months and so on for any month of the planning period. At the third month, the return amount represented by a percentage of items that were sold in the first, second and third months, respectively. Generally, the return rate is as follows:

$$
R(t)=h(t) D(1)+h(t-1) D(2)+h(t-2) D(3)+\cdots ; \quad t=1,2, \ldots, T
$$

where $h(0)=h(-1)=h(-2)=\cdots=0$. 


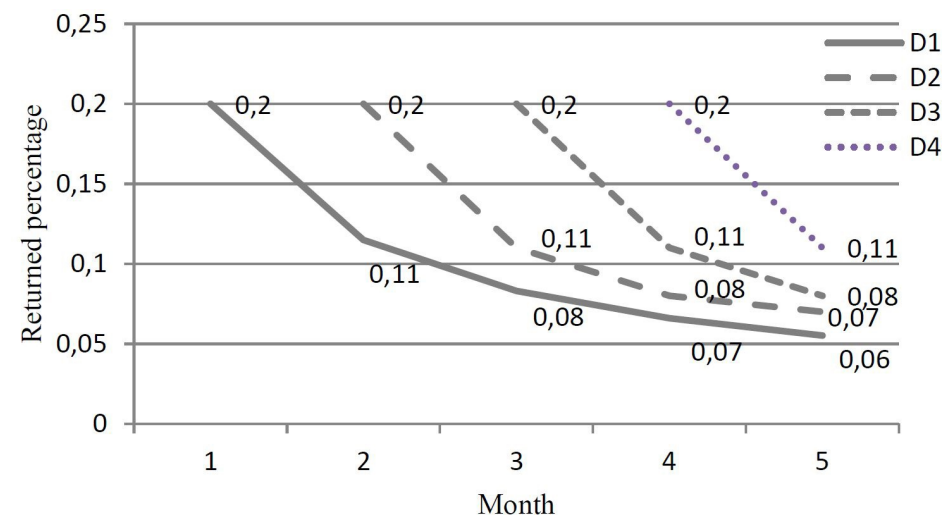

Figure 1 - Returned percentage of product.

\subsection{Optimal control model}

In this section, a discussion of the development of three models of inventory control under periodic review policy will be described. The first one considers the remanufacturing process as being continuous over the planning period (without disposal option). Remanufacturing process that happens in the second part of the planning period (disposal happens at arrival) will be discussed in the second model. The last model is constrained by a specific percent of remanufacturing product (disposal of serviceable products to control on inventory). Practically, these models can be used in many industrial fields, such as electronic and electrical industries. These models represent three practical situations of remanufacturing and disposal. For example, a firm that manufactures a blender and has specific goals related to rates of manufacturing and remanufacturing, as well as the level of safety stock. Minimizing the total cost can be achieved by meeting the demands and putting the inventory at a specific level with many choices of remanufacturing and disposal items.

\subsubsection{The first model}

Figure 2 shows the hybrid inventory system of the first model.

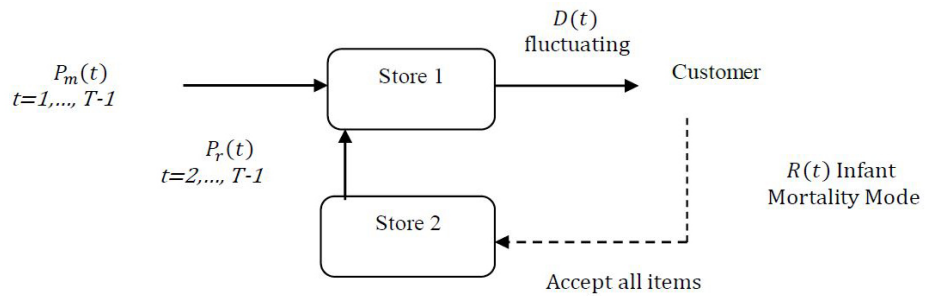

Figure 2 - The hybrid inventory system of the first model. 
The objective function can be expressed as the quadratic form to be minimized (Hull, 2003; Sethi \& Thompson, 2000):

$$
2 J=\sum_{t=1}^{T-1} c_{1}\left\{I_{1}(t)-\hat{I}_{1}\right\}^{2}+c_{2}\left\{I_{2}(t)-\hat{I}_{2}\right\}^{2}+k_{m}\left\{P_{m}(t)-\hat{P}_{m}(t)\right\}^{2}+k_{r}\left\{P_{r}(t)-\hat{P}_{r}(t)\right\}^{2}
$$

subject to the state equations:

$$
\begin{aligned}
& \Delta I_{1}(t)=P_{m}(t)+P_{r}(t)-D(t) \\
& \Delta I_{2}(t)=R(t)-P_{r}(t)
\end{aligned}
$$

with initial condition $I_{1}(1)=I_{1}, I_{2}(1)=I_{2}$, where $\Delta I(t)=I(t+1)-I(t)$ is called the difference operator.

Equation (4) represents the minimizing of the total of mean square deviation of inventory levels and rates of manufacturing and remanufacturing from its goals, respectively. Meanwhile, Eq. (5) represents the inventory level in the first stock that is increased by manufacturing and remanufacturing rates, as well as decreased by the demand rate. Items in the second stock are increased by the return rate and decreased by the remanufacturing rate (Eq. 6).

To solve this problem, we use Pontryagin's maximum principles, the Lagrangian function is:

$$
\begin{aligned}
L= & \sum_{t=1}^{T-1}-\frac{1}{2}\left[c_{1}\left\{I_{1}(t)-\hat{I}_{1}\right\}^{2}+c_{2}\left\{I_{2}(t)-\hat{I}_{2}\right\}^{2}+k_{m}\left\{P_{m}(t)-\hat{P}_{m}(t)\right\}^{2}+k_{r}\left\{P_{r}(t)-\hat{P}_{r}(t)\right\}^{2}\right] \\
& +\sum_{t=1}^{T-1} \lambda_{1}(t+1)\left[P_{m}(t)+P_{r}(t)-D(t)-I_{1}(t+1)+I_{1}(t)\right] \\
& +\sum_{t=1}^{T-1} \lambda_{2}(t+1)\left[R(t)-P_{r}(t)-I_{2}(t+1)+I_{2}(t)\right]
\end{aligned}
$$

A Hamiltonian function defined as:

$$
\begin{aligned}
H(t)= & \frac{-1}{2}\left[c_{1}\left\{I_{1}(t)-\hat{I}_{1}\right\}^{2}+c_{2}\left\{I_{2}(t)-\hat{I}_{2}\right\}^{2}+k_{m}\left\{P_{m}(t)-\hat{P}_{m}(t)\right\}^{2}+k_{r}\left\{P_{r}(t)-\hat{P}_{r}(t)\right\}^{2}\right] \\
& +\lambda_{1}(t+1)\left[P_{m}(t)+P_{r}(t)-D(t)\right]+\lambda_{2}(t+1)\left[R(t)-P_{r}(t)\right]
\end{aligned}
$$

By using Eq. (8), we can write Eq. (7) as follows:

$$
L=\sum_{t=1}^{T-1} H(t)-\lambda_{1}(t+1)\left\{I_{1}(t+1)-I_{1}(t)\right\}-\lambda_{2}(t+1)\left\{I_{2}(t+1)-I_{2}(t)\right\}
$$

Now, differentiate Eq. (9) with respect to $I(t)$ to get on the adjoint equations:

$$
\begin{aligned}
& \Delta \lambda_{1}(t)=c_{1}\left\{I_{1}(t)-\hat{I}_{1}\right\} \\
& \Delta \lambda_{2}(t)=c_{2}\left\{I_{2}(t)-\hat{I}_{2}\right\}
\end{aligned}
$$


To get on the rates of manufacturing and remanufacturing, we differentiate Eq. (9) with respect to $P_{m}(t)$ and $P_{r}(t)$ to yield:

$$
\begin{aligned}
P_{m}(t) & =\hat{P}_{m}(t)+\frac{1}{k_{m}} \lambda_{1}(t+1) ; t=1,2, \ldots, T-1 \\
P_{r}(t) & =\hat{P}_{r}(t)+\frac{1}{k_{r}}\left\{\lambda_{1}(t+1)-\lambda_{2}(t+1)\right\} ; t=2,3, \ldots, T-1
\end{aligned}
$$

Practically, the remanufacturing process happens one month later due to the fact that it depends on the products that were returned from customers. To constrain the rates of manufacturing and remanufacturing by non-negative values, Eqs. (12) and (13) become:

$$
\begin{aligned}
P_{m}(t) & =\operatorname{Max}\left\{\hat{P}_{m}(t)+\frac{1}{k_{m}} \lambda_{1}(t+1), 0\right\} ; t=1,2, \ldots, T-1 \\
P_{r}(t) & =\left\{\begin{array}{c}
\operatorname{Max}\left[\hat{P}_{r}(t)+\frac{1}{k_{r}}\left\{\lambda_{1}(t+1)-\lambda_{2}(t+1)\right\}, 0\right] ; t=2,3, \ldots, T-1 \\
0 ; t=1
\end{array}\right.
\end{aligned}
$$

The goal rates of manufacturing and remanufacturing must satisfy the state equations 5 and 6 , respectively:

$$
\begin{aligned}
& \hat{P}_{m}(t)=D(t)-\hat{P}_{r}(t) ; t=1,2, \ldots, T-1 \\
& \hat{P}_{r}(t)=\left\{\begin{array}{c}
R(t-1) ; t=2,3, \ldots, T-1 \\
0 ; t=1
\end{array}\right.
\end{aligned}
$$

Substituting Eqs. (12, 13, 16 and 17) into Eq. (5) yields:

$$
\Delta I_{1}(t)=\frac{1}{k_{m}} \lambda_{1}(t+1)+\frac{1}{k_{r}}\left\{\lambda_{1}(t+1)-\lambda_{2}(t+1)\right\}
$$

Substituting Eqs. (13, 16 and 17) into Eq. (6) yields:

$$
\Delta I_{2}(t)=\frac{1}{k_{r}}\left\{\lambda_{1}(t+1)-\lambda_{2}(t+1)\right\}
$$

From Eqs. (10, 11, 18 and 19), we obtained a system of difference equations. This boundary value problem can be solved numerically by Microsoft Excel, with the initial condition $I(1)=I_{1}$ and terminal condition $\lambda(T)=0$.

\subsubsection{The second model}

In this model, we assume that the remanufacturing process will happen in the second part of the planning period. This means that the demand at the first part of the planning period will be satisfied by manufacturing only, while it satisfies both manufacturing and remanufacturing in the second part.

Figure 3 shows the hybrid inventory system of the second model. 


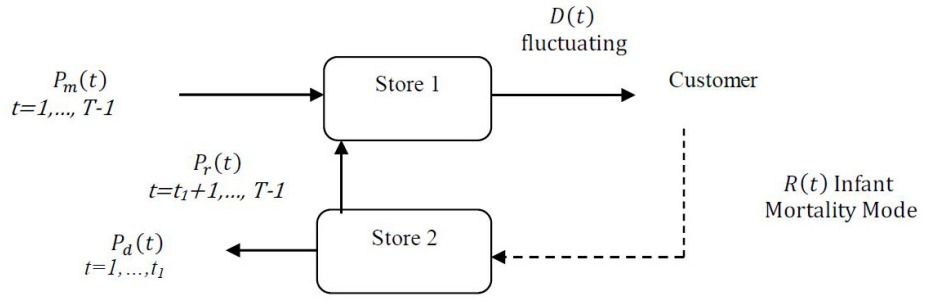

Figure 3 - The hybrid inventory system of the second model.

The change will happen in the state equations with the objective function remaining unchanged (Eq. 4).

$$
\begin{aligned}
& \Delta I_{1}(t)=P_{m}(t)-D(t) ; t=1,2, \ldots, t_{1} \\
& \Delta I_{2}(t)=R(t)-P_{d}(t) ; t=1,2, \ldots, t_{1} \\
& \Delta I_{1}(t)=P_{m}(t)+P_{r}(t)-D(t) ; t=t_{1}+1, \ldots, T-1 \\
& \Delta I_{2}(t)=R(t)-P_{r}(t) ; t=t_{1}+1, \ldots, T-1
\end{aligned}
$$

By using Pontryagin's maximum principles that have been described in the first model, we can find the solution to the problem.

The manufacturing rate is similar to the first model (Eq. 14), with a change in the goal rate as follows:

$$
\hat{P}_{m}(t)=\left\{\begin{array}{c}
D(t) ; t=1,2, \ldots, t_{1} \\
D(t)-\hat{P}_{r}(t) ; t=t_{1}+1, \ldots, T-1
\end{array}\right.
$$

The remanufacturing rate and its goal are as follows:

$$
\begin{gathered}
\hat{P}_{r}(t)=\left\{\begin{array}{c}
0 ; t=1,2, \ldots, t_{1} \\
R(t-1) ; t=t_{1}+1, \ldots, T-1
\end{array}\right. \\
P_{r}(t)=\left\{\begin{array}{c}
0 ; t=1,2, \ldots, t_{1} \\
\operatorname{Max}\left[\hat{P}_{r}(t)-\frac{1}{k_{r}}\left\{\lambda_{1}(t+1)+\lambda_{2}(t+1)\right\}, 0\right] ; t=t_{1}+1, \ldots, T-1
\end{array}\right.
\end{gathered}
$$

The disposal rate and its goal are as follows:

$$
\begin{gathered}
\hat{P}_{d}(t)=\left\{\begin{array}{c}
R(t-1) ; t=2, \ldots, t_{1} \\
0 ; t=t_{1}+1, \ldots, T-1
\end{array}\right. \\
P_{d}(t)=\left\{\begin{array}{c}
\operatorname{Max}\left[\begin{array}{c}
\left.\hat{P}_{d}(t)-\frac{1}{k_{d}} \lambda_{2}(t+1), 0\right] ; t=1, \ldots, t_{1} \\
0 ; t=t_{1}+1, \ldots, T-1
\end{array}\right.
\end{array}\right.
\end{gathered}
$$


Substituting Eqs. (12, 24-26) into Eqs. (20 and 22) yields:

$$
\Delta I_{1}(t)=\left\{\begin{array}{c}
\frac{1}{k_{m}} \lambda_{1}(t+1) ; t=0,1, \ldots, t_{1} \\
\frac{1}{k_{m}} \lambda_{1}(t+1)+\frac{1}{k_{r}}\left\{\lambda_{1}(t+1)-\lambda_{2}(t+1)\right\} ; t=t_{1}+1, \ldots, T-1
\end{array}\right.
$$

Substituting Eqs. (25 and 26) into Eqs. (21 and 23) yields

$$
\Delta I_{2}(t)=\left\{\begin{array}{c}
R(t) ; t=1, \ldots, t_{1} \\
\frac{1}{k_{r}}\left\{\lambda_{1}(t+1)-\lambda_{2}(t+1)\right\} ; t=t_{1}+1, \ldots, T-1
\end{array}\right.
$$

The adjoining equations (10 and 11) remain unchanged. Using the solver function in the Microsoft Excel by applying the condition $\lambda(T)=0$ by changing the value of $\lambda(1)$, we can find the inventory levels and $\lambda(t)$ by solving Eqs. (10, 11, 29 and 30) simultaneously. Then, we can determine the rates of manufacturing and remanufacturing using Eqs. (14) and (26), respectively.

\subsubsection{The third model}

In this model, we assume the remanufacturing items that were sold as a new product must not exceed a specific percentage of demand. All returned items will be remanufactured and stored in the first store. Part of remanufactured items are sold as a new product, and the remaining are disposed to the second market to avoid an increase in the inventory level.

$$
P_{d}(t) \geq R(t-1)-\vartheta \mathrm{D}(t) ; 0<\vartheta<1
$$

Figure 4 shows the hybrid inventory system of the third model.

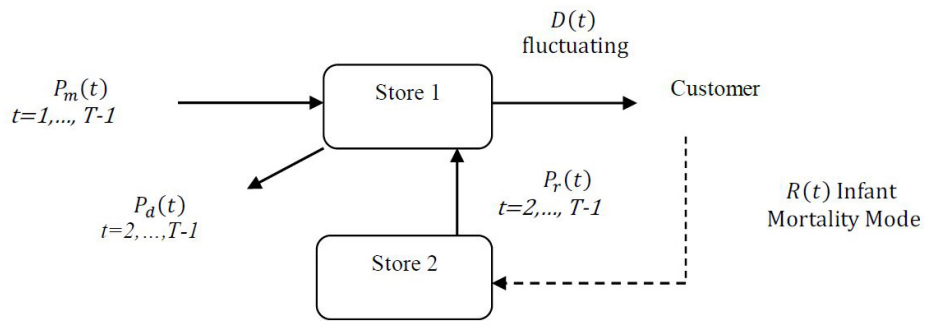

Figure 4 - The hybrid inventory system of the third model.

Condition 31 is added to the optimal control problem as a new constraint, then the problem is solved by using Lagrange multiplier with three constraints (Hull, 2003; Sethi \& Thompson, 2000). In this paper, we use another approach by achieving the condition 31 through rates of manufacturing and remanufacturing directly. 
The objective function can be expressed as the quadratic form to be minimized:

$$
\begin{aligned}
2 J= & \sum_{t=1}^{T-1} c_{1}\left\{I_{1}(t)-\hat{I}_{1}\right\}^{2}+c_{2}\left\{I_{2}(t)-\hat{I}_{2}\right\}^{2}+k_{m}\left\{P_{m}(t)-\hat{P}_{m}(t)\right\}^{2} \\
& +k_{r}\left\{P_{r}(t)-\hat{P}_{r}(t)\right\}^{2}+k_{d}\left\{P_{d}(t)-\hat{P}_{d}(t)\right\}^{2}
\end{aligned}
$$

subject to the state equations:

$$
\begin{aligned}
& \Delta I_{1}(t)=P_{m}(t)+P_{r}(t)-P_{d}(t)-D(t) ; t=1, \ldots, T-1 \\
& \Delta I_{2}(t)=R(t)-P_{r}(t) ; t=1, \ldots, T-1
\end{aligned}
$$

By using Pontryagin's maximum principles that have been described in the first model, we can find the solution to the problem.

The rates of manufacturing, remanufacturing and disposal and its goal are as follows:

$$
\begin{aligned}
& \hat{P}_{r}(t)=R(t-1) ; t=2, \ldots, T-1 \\
& P_{r}(t)=\hat{P}_{r}(t)+\frac{1}{k_{r}}\left\{\lambda_{1}(t+1)-\lambda_{2}(t+1)\right\} ; t=2, \ldots, T-1 \\
& \hat{P}_{d}(t)=\left\{\begin{array}{c}
\hat{P}_{r}(t)-\vartheta \mathrm{D}(t) ; \hat{P}_{r}(t)>\vartheta \mathrm{D}(t) \\
0 ; \hat{P}_{r}(t) \leq \vartheta \mathrm{D}(t)
\end{array} \quad t=2, \ldots, T-1\right. \\
& P_{d}(t)=\left\{\begin{array}{c}
\hat{P}_{d}(t)-\frac{1}{k_{d}} \lambda_{1}(t+1) ; \hat{P}_{d}(t)>\frac{1}{k_{d}} \lambda_{1}(t+1) \\
0 ; \hat{P}_{d}(t) \leq \frac{1}{k_{d}} \lambda_{1}(t+1)
\end{array} \quad t=2, \ldots, T-1\right. \\
& \hat{P}_{m}(t)=D(t)+\hat{P}_{d}(t)-\hat{P}_{r}(t) ; t=1,2, \ldots, T-1 \\
& P_{m}(t)=\left\{\begin{array}{c}
\hat{P}_{m}(t)+\frac{1}{k_{m}} \lambda_{1}(t+1) ; \hat{P}_{m}(t)>\frac{1}{k_{m}} \lambda_{1}(t+1) \\
0 ; \hat{P}_{m}(t) \leq \frac{1}{k_{m}} \lambda_{1}(t+1)
\end{array} \quad t=1,2, \ldots, T-1\right.
\end{aligned}
$$

Substituting Eqs. (35-40) into Eqs. (33 and 34) yields:

$$
\begin{aligned}
& \Delta I_{1}(t)=\left(\frac{1}{k_{m}}+\frac{1}{k_{d}}\right) \lambda_{1}(t+1)+\frac{1}{k_{r}}\left\{\lambda_{1}(t+1)-\lambda_{2}(t+1)\right\} \\
& \Delta I_{2}(t)=-\frac{1}{k_{r}}\left\{\lambda_{1}(t+1)-\lambda_{2}(t+1)\right\}
\end{aligned}
$$

\section{RESULTS AND DISCUSSION}

An inventory system with the following parameter values:

- $\widehat{I}_{1}=50$ items; $\widehat{I}_{2}=30$ items.

The inventory goal level, and the safety stock that faced the demand fluctuation. 
- $I_{1}(1)=70$ items; $I_{2}(1)=10$ items.

The initial inventory levels that mean the items amount in the stock at the beginning of the planning period.

- $T=10$ months.

The length of the planning period.

- $t_{1}=5$.

The time of the beginning of the remanufacturing process.

- $k_{m}=5 \$ ; k_{r}=3 \$ ; k_{d}=2 \$ ; c_{1}=2 \$ ; c_{2}=2 \$$.

The penalty costs, which determines the priority of achieving the goals of inventory, manufacturing and remanufacturing.

- $\mathrm{D}(t)=100+40 * \operatorname{Sin}(t)$.

The supposing demand that affects the rates of manufacturing and remanufacturing. There is no effect on achieving the goals of inventory and manufacture by choosing another demand function, the effect only on the manufacture amount.

- $\vartheta=0.4 ; \gamma=0.08$.

The distribution parameters.

The purpose of developing three models of inventory control is to introduce several strategies to the decision maker that is suitable in the practical situation of the company. Also, determine the optimal policy of remanufacturing and disposal items that minimize the total cost. The changing in the value of the Weibull parameter and the upper level of remanufacturing show the relationship between the rates of return, manufacturing, disposal and remanufacturing. Therefore, several choices to the decision maker, according to the practical situation.

\subsection{Solution of the optimal control model}

By using the solver function in Excel with condition $\lambda(T)=0$, we can solve for the three models. Practical situations with any amounts of demand and inventory can be solved the same way.

From Figures (5 and 6), the inventory levels of the three models (FM, SM and TM) converge to its goal level (I.G) over time. This means that there is a control over the inventory level despite a difference in the rates of manufacturing and remanufacturing.

From Figures (7, 8 and 9), the rates of manufacturing and remanufacturing differ between the three models, but it achieves its goals in satisfying the collective demand and defines inventory levels as specific levels (goal levels). Figure 8 shows that the remanufacturing process started from the second part of the planning period, while manufacturing and remanufacturing processes that started together (at the beginning of the planning period) are shown in Figures 7 and 9. Figure 10 shows the total returned products $R(t)$ that increase with time due to increasing products 


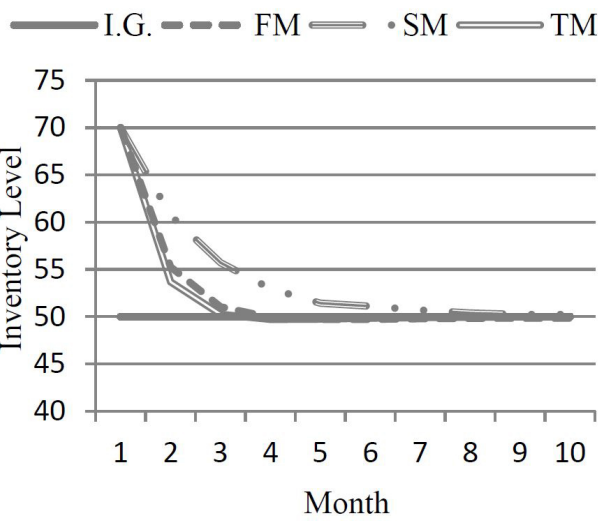

Figure 5 - The inventory level of the first store.

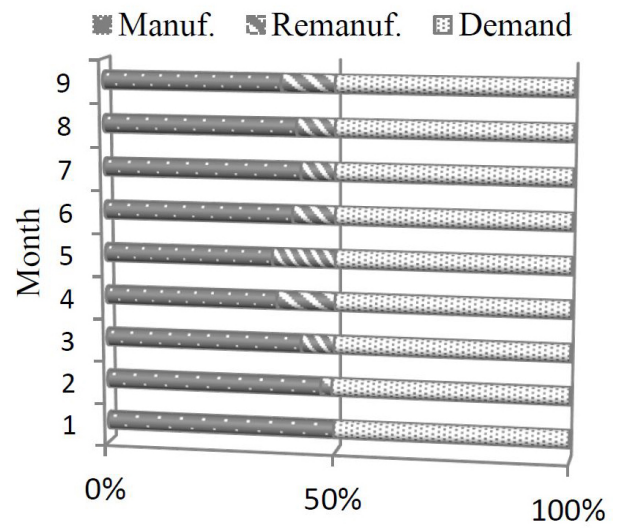

Figure 7 - The percentage of manuf. and remanuf. of the first model.

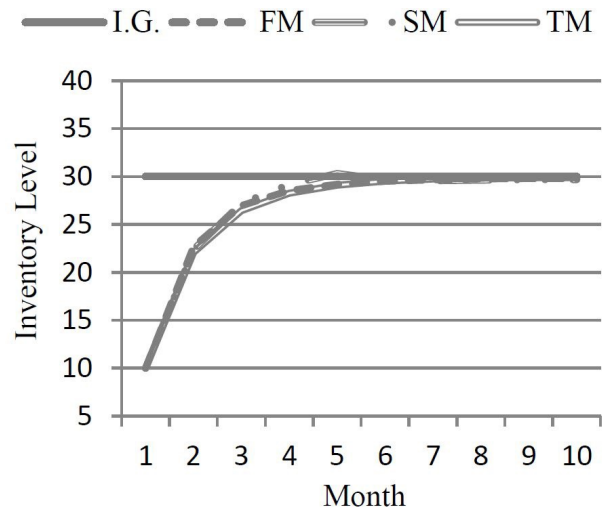

Figure 6 - The inventory level of the second store.

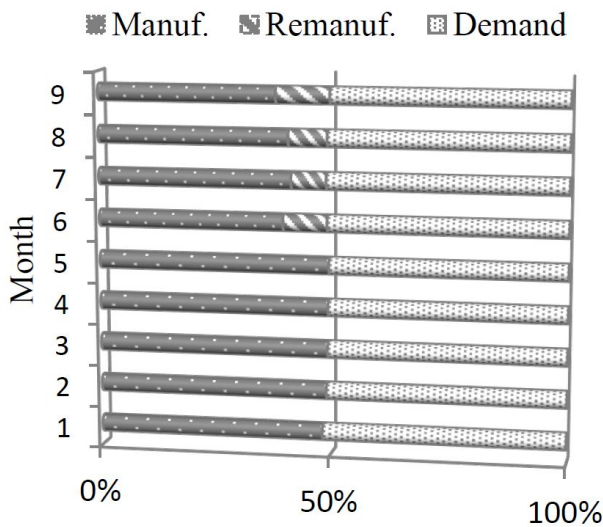

Figure 8 - The percentage of manuf. and remanuf. of the second model.

that are supplied to customers over time. It also shows returned products from a monthly demand over the planning period, which appears as an infant mortality mode (decreasing curve).

The main target of developing of the optimal control model is achieved by controlling the inventory levels as the decision maker desired, and at the same time satisfies the demand. The change in the rates of control variables (manufacturing and remanufacturing rates) helps satisfy the demands and put the state variables (inventory level) at a specific level for three practical situations (three models).

\subsection{Sensitivity analysis}

Sensitivity analysis was performed to clarify the effect of the Weibull parameter value (as shown in Tables 2, 3 and 4), and the percentage of the remanufacturing items that were sold as new products (as shown in Tables 5, 6 and 7) on the results. Conclusions of sensitivity analysis of the 


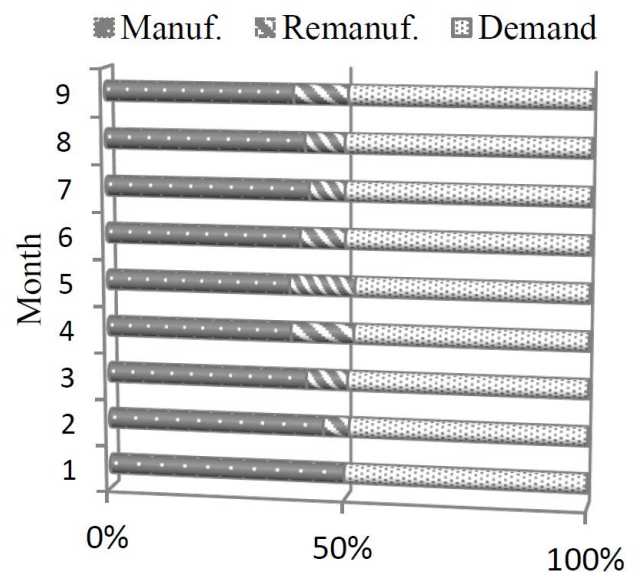

Figure 9 - The percentage of manuf. and remanuf. of the third model.

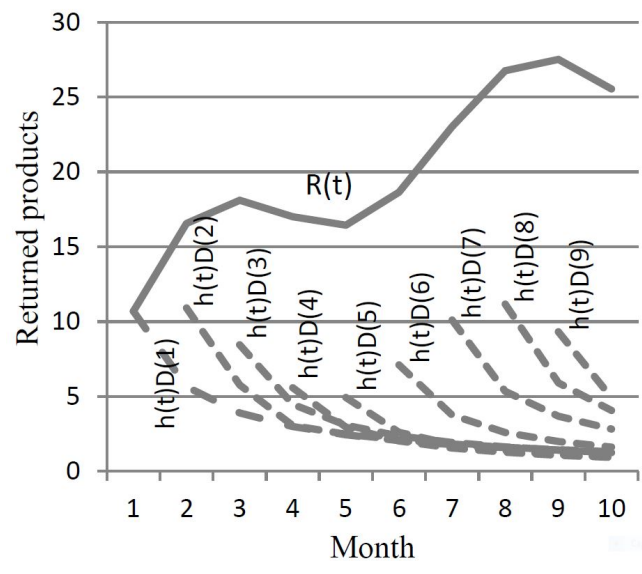

Figure 10 - Returned products, according to months.

effect of Weibull parameters on the results are the same for three models, so we applied them only on the first model.

Table 2 - Solution of the first model with $\gamma=0.08$.

\begin{tabular}{c|c|c|c|c|c|c|c|c|c}
\hline Month & $I_{1}$ & $I_{2}$ & $P_{m}$ & $P_{r}$ & $\hat{P}_{m}$ & $\hat{P}_{r}$ & $R$ & $D$ & $J$ \\
\hline 1 & 70.00 & 10.00 & 131.61 & 0.00 & 133.66 & 0.00 & 10.69 & 133.66 & 810.53 \\
\hline 2 & 55.27 & 22.68 & 125.73 & 6.40 & 125.68 & 10.69 & 16.56 & 136.37 & 108.92 \\
\hline 3 & 51.03 & 26.97 & 89.55 & 14.98 & 89.08 & 16.56 & 18.11 & 105.64 & 14.54 \\
\hline 4 & 49.93 & 28.54 & 52.06 & 17.46 & 51.62 & 18.11 & 17.00 & 69.73 & 3.25 \\
\hline 5 & 49.71 & 29.20 & 44.97 & 16.69 & 44.64 & 17.00 & 16.44 & 61.64 & 1.13 \\
\hline 6 & 49.73 & 29.51 & 72.60 & 16.27 & 72.39 & 16.44 & 18.64 & 88.82 & 0.47 \\
\hline 7 & 49.78 & 29.67 & 107.77 & 18.56 & 107.64 & 18.64 & 23.02 & 126.28 & 0.21 \\
\hline 8 & 49.83 & 29.75 & 116.62 & 22.98 & 116.56 & 23.02 & 26.76 & 139.57 & 0.10 \\
\hline 9 & 49.85 & 29.79 & 89.72 & 26.76 & 89.72 & 26.76 & 27.51 & 116.48 & 0.07 \\
\hline 10 & 49.85 & 29.79 & & & & & & & 0.07 \\
\hline
\end{tabular}

Table 2 shows the rates of manufacturing and remanufacturing close to its goals in the first months of the planning period. Therefore, the total penalty costs are minimized over time. During the second month, the remanufacturing rate is less than its goal (returned product) in increasing its inventory level of the second store to its goal. Also, part of the inventory of the first store was used to satisfy the demand to reduce inventory levels to its goal.

We can deduce from Tables 2, 3 and 4 that the returned product increases with the increase in the Weibull parameter values, thus increasing the remanufacturing rate and decreasing the manufacturing rate, and vice versa. The remanufacturing rate depends on the amount of the 
Table 3 - Solution of the first model with $\gamma=0.16$.

\begin{tabular}{c|c|c|c|c|c|c|c|c}
\hline Month & $I_{1}$ & $I_{2}$ & $P_{m}$ & $P_{r}$ & $\hat{P}_{m}$ & $\hat{P}_{r}$ & $R$ & $J$ \\
\hline 1 & 70.00 & 10.00 & 131.61 & 0.00 & 133.66 & 0.00 & 21.39 & 810.53 \\
\hline 2 & 55.27 & 22.68 & 115.04 & 17.10 & 114.99 & 21.39 & 33.77 & 108.92 \\
\hline 3 & 51.03 & 26.97 & 72.35 & 32.19 & 71.88 & 33.77 & 37.59 & 14.54 \\
\hline 4 & 49.93 & 28.54 & 32.58 & 36.94 & 32.14 & 37.59 & 35.94 & 3.25 \\
\hline 5 & 49.71 & 29.20 & 26.02 & 35.63 & 25.70 & 35.94 & 35.16 & 1.13 \\
\hline 6 & 49.73 & 29.51 & 53.88 & 34.99 & 53.67 & 35.16 & 39.82 & 0.47 \\
\hline 7 & 49.78 & 29.67 & 86.59 & 39.74 & 86.46 & 39.82 & 48.93 & 0.21 \\
\hline 8 & 49.83 & 29.75 & 90.70 & 48.90 & 90.64 & 48.93 & 56.97 & 0.10 \\
\hline 9 & 49.85 & 29.79 & 59.52 & 56.97 & 59.52 & 56.97 & 59.08 & 0.07 \\
\hline 10 & 49.85 & 29.79 & & & & & & 0.07 \\
\hline
\end{tabular}

Table 4 - Solution of the first model with $\gamma=0.04$.

\begin{tabular}{c|c|c|c|c|c|c|c|c}
\hline Month & $I_{1}$ & $I_{2}$ & $P_{m}$ & $P_{r}$ & $\hat{P}_{m}$ & $\hat{P}_{r}$ & $R$ & $J$ \\
\hline 1 & 70.00 & 10.00 & 131.61 & 0.00 & 133.66 & 0.00 & 5.35 & 810.53 \\
\hline 2 & 55.27 & 22.68 & 131.08 & 1.06 & 131.03 & 5.35 & 8.20 & 108.92 \\
\hline 3 & 51.03 & 26.97 & 97.91 & 6.63 & 97.44 & 8.20 & 8.89 & 14.54 \\
\hline 4 & 49.93 & 28.54 & 61.28 & 8.24 & 60.84 & 8.89 & 8.27 & 3.25 \\
\hline 5 & 49.71 & 29.20 & 53.69 & 7.96 & 53.37 & 8.27 & 7.95 & 1.13 \\
\hline 6 & 49.73 & 29.51 & 81.09 & 7.79 & 80.87 & 7.95 & 9.03 & 0.47 \\
\hline 7 & 49.78 & 29.67 & 117.38 & 8.94 & 117.25 & 9.03 & 11.18 & 0.21 \\
\hline 8 & 49.83 & 29.75 & 128.46 & 11.14 & 128.40 & 11.18 & 12.99 & 0.10 \\
\hline 9 & 49.85 & 29.79 & 103.50 & 12.99 & 103.50 & 12.99 & 13.30 & 0.07 \\
\hline 10 & 49.85 & 29.79 & & & & & & 0.07 \\
\hline
\end{tabular}

returned items, therefore, there is a positive relation between them. Practically, the demand will be satisfied by manufacturing and remanufacturing together, so when any of them increases, that means the second one will decrease. Meanwhile, the inventory levels and total cost are insensitive towards changing values of the Weibull parameter. Inventory levels are state variables that are controlled by the control variables (rates of manufacturing and remanufacturing), so it is not affected by changes in the Weibull parameters. The total penalty cost represents the difference between the inventory level and its goals, in addition to the difference between rates of manufacturing and remanufacturing, and its goals. The amount of difference is the same with any value of the Weibull parameters, so the total cost does not change with the changing of Weibull parameters.

From Table 5, the constraint of the remanufacturing items that have been sold is achieved. There are no disposal items because all returned items that were remanufactured are less than the specified percentage of demand $\vartheta \mathrm{D}$. 
Table 5 - Solution of the third model with $\vartheta=0.4$.

\begin{tabular}{c|c|c|c|c|c|c|c}
\hline Month & $I_{1}$ & $I_{2}$ & $P_{m}$ & $P_{r}$ & $\vartheta \mathrm{D}$ & $P_{d}$ & $J$ \\
\hline 1 & 70.00 & 10.00 & 132.45 & 0.00 & 53.46 & 0 & 803.65 \\
\hline 2 & 53.68 & 22.09 & 125.94 & 15.05 & 54.55 & 0 & 104.82 \\
\hline 3 & 50.25 & 26.44 & 89.45 & 18.38 & 42.26 & 0 & 18.00 \\
\hline 4 & 49.71 & 28.26 & 51.87 & 18.96 & 27.89 & 0 & 4.35 \\
\hline 5 & 49.74 & 29.10 & 44.79 & 17.42 & 24.66 & 0 & 1.19 \\
\hline 6 & 49.83 & 29.53 & 72.47 & 16.65 & 35.53 & 0 & 0.34 \\
\hline 7 & 49.90 & 29.74 & 107.68 & 18.75 & 50.51 & 0 & 0.10 \\
\hline 8 & 49.94 & 29.85 & 116.57 & 23.06 & 55.83 & 0 & 0.03 \\
\hline 9 & 49.96 & 29.89 & 89.72 & 26.76 & 46.59 & 0 & 0.01 \\
\hline 10 & 49.96 & 29.89 & & & & & 0.01 \\
\hline
\end{tabular}

Table 6 - Solution of the third model with $\vartheta=0.2$.

\begin{tabular}{c|c|c|c|c|c|c|c}
\hline Month & $I_{1}$ & $I_{2}$ & $P_{m}$ & $P_{r}$ & $\vartheta \mathrm{D}$ & $P_{d}$ & $J$ \\
\hline 1 & 70.00 & 10.00 & 132.45 & 0.00 & 26.73 & 0.00 & 803.65 \\
\hline 2 & 53.68 & 22.09 & 125.94 & 15.05 & 27.27 & 0.00 & 104.82 \\
\hline 3 & 50.25 & 26.44 & 89.45 & 18.38 & 21.13 & 0.00 & 18.00 \\
\hline 4 & 49.71 & 28.26 & 56.03 & 18.96 & 13.95 & 3.54 & 4.74 \\
\hline 5 & 49.74 & 29.10 & 49.46 & 17.42 & 12.33 & 4.31 & 1.32 \\
\hline 6 & 49.83 & 29.53 & 72.47 & 16.65 & 17.76 & 0.00 & 0.34 \\
\hline 7 & 49.90 & 29.74 & 107.68 & 18.75 & 25.26 & 0.00 & 0.10 \\
\hline 8 & 49.94 & 29.85 & 116.57 & 23.06 & 27.91 & 0.00 & 0.03 \\
\hline 9 & 49.96 & 29.89 & 93.19 & 26.76 & 23.30 & 3.47 & 0.01 \\
\hline 10 & 49.96 & 29.89 & & & & & 0.01 \\
\hline
\end{tabular}

We can deduce from Tables 5, 6 and 7 that the disposal rate increases with the decrease in the $\vartheta$ value, thus decreasing the number of the remanufacturing items that were sold and increasing the manufacturing rate, and vice versa. There is an opposite relation between the disposal rate and the $\vartheta$ value. The amount of remanufacturing items depends on the demand percent $\vartheta \mathrm{D}$ that will be satisfied by remanufacturing. Therefore, increasing the value of $\vartheta D$ leads to increased remaufacturing and decreased disposal, and vice versa. Meanwhile, the inventory levels and total cost are insensitive towards the change in the $\vartheta$ value.

\section{CONCLUSION AND RECOMMENDATIONS}

In this paper, we discussed the infant mortality mode to describe the returned products, that have been returned after use, in the hybrid manufacturing-inventory system. The Hazard function of the Weibull distribution as a return rate was addressed. We developed three models of optimal control to determine the optimal policy of remanufacturing with three disposal options. Our mod- 
Table 7 - Solution of the third model with $\vartheta=0.1$.

\begin{tabular}{c|c|c|c|c|c|c|c}
\hline Month & $I_{1}$ & $I_{2}$ & $P_{m}$ & $P_{r}$ & $\vartheta \mathrm{D}$ & $P_{d}$ & $J$ \\
\hline 1 & 70.00 & 10.00 & 132.45 & 0.00 & 13.37 & 0.00 & 803.65 \\
\hline 2 & 53.68 & 22.09 & 125.94 & 15.05 & 13.64 & 0.00 & 104.82 \\
\hline 3 & 50.25 & 26.44 & 95.45 & 18.38 & 10.56 & 5.08 & 18.00 \\
\hline 4 & 49.71 & 28.26 & 63.01 & 18.96 & 6.97 & 10.51 & 4.74 \\
\hline 5 & 49.74 & 29.10 & 55.63 & 17.42 & 6.16 & 10.47 & 1.32 \\
\hline 6 & 49.83 & 29.53 & 80.02 & 16.65 & 8.88 & 7.35 & 0.34 \\
\hline 7 & 49.90 & 29.74 & 113.69 & 18.75 & 12.63 & 5.91 & 0.10 \\
\hline 8 & 49.94 & 29.85 & 125.63 & 23.06 & 13.96 & 9.02 & 0.03 \\
\hline 9 & 49.96 & 29.89 & 104.84 & 26.76 & 11.65 & 15.11 & 0.01 \\
\hline 10 & 49.96 & 29.89 & & & & & 0.01 \\
\hline
\end{tabular}

els discussed three practical situations of disposal and remanufacturing of items, and determined the return amount carefully, which affected the remanufacturing rate. Moreover, it simplified the optimal control model of the third model to obtain results.

In our models, the results of the model with continuous remanufacturing over time are better than remanufacturing that happened in the second part of the planning period. The infant mortality mode is suitable for describing the returned rate of products that showed its defects after use, such as electronic devices. Moreover, increasing the value of Weibull distribution means reducing the product's lifetime, which increases remanufacturing and decreases manufacturing. The control of the percentage of remanufacturing, according to the manufacturing rate, was achieved. Sensitivity analysis showed the balance between the rates of manufacturing, remanufacturing and disposal in all cases to satisfy demands and maintain the inventory levels at a specific level. Economically, these hybrid models were found to be effective for inventory control. The model can be applied in the case of multiple products with multi production lines by taking every production line that represents a specific product separately. This study could be extended to include stochastic demand and shortage that happen when the demand is higher than manufacturing and remanufacturing rates. Also, the limited manufacturing rate is another case that can be discussed, which means focusing on the remanufacturing to satisfy demand.

\section{ACKNOWLEDGEMENT}

The author expresses heartfelt gratitude to the referees for their several useful comments and valuable suggestions.

\section{REFERENCES}

[1] Chung SL, WeE HM \& YANG PC. 2008. Optimal policy for a closed-loop supply chain inventory system with remanufacturing. Mathematical and Computer Modelling, 48(5-6): 
$867-881$.

[2] CORUM A, VAYVAY Ö \& BAYRAKTAR E. 2014. The impact of remanufacturing on total inventory cost and order variance. Journal of cleaner production, 85: 442-452.

[3] Dhaiban AK, Baten MA \& AzIZ N. 2018. An optimal inventory control in hybrid manufacturing/remanufacturing system with deteriorating and defective items. International Journal of Mathematics in Operational Research, 12(1): 66-90.

[4] FLAPPER SD, GAYON JP \& LIM LL. 2014. On the optimal control of manufacturing and remanufacturing activities with a single shared server. European Journal of Operational Research, 234(1): 86-98.

[5] Gallo M, Guerra L \& Guizzi G. 2009. Hybrid remanufacturing/manufacturing systems: secondary markets issues and opportunities. WSEAS Transactions on Business and Economics, 6(1): 31-41.

[6] Gayon JP, Vercraene S \& Flapper SDP. 2017. Optimal control of a productioninventory system with product returns and two disposal options. European Journal of Operational Research, pp. 1-33.

[7] Guo J \& YA G. 2015. Optimal strategies for manufacturing/remanufacturing system with the consideration of recycled products. Computers \& Industrial Engineering, pp. 1-9.

[8] GuO JQ \& LiAnG CJ. 2011. Models for recycling and production policy for a closedloop system. Journal of Quality, 18(4): 303-314.

[9] Hartzell AL, Da Silva MG \& Shea HR. 2011. MEMS reliability. Springer Science \& Business Media. tRANSDUCERS, Solid-State. 36.

[10] Hsuen CF. 2010. Inventory Control for Stochastic Reverse Logistics with Product's Life Cycle. In: Proceedings of the World Congress on Engineering, vol. III. pp. 2-7. London, U.K.

[11] Hull DG. 2003. Optimal control theory for applications. Springer.

[12] Jin X, Ni J \& Koren Y. 2011. Optimal control of reassembly with variable quality returns in a product remanufacturing system. CIRP Annals - Manufacturing Technology, 60(1): 25-28.

[13] KAYA O. 2010. Incentive and production decisions for remanufacturing operations. European Journal of Operational Research, 201(2): 442-453.

[14] Kim E, Saghafian S \& VAn Oyen MP. 2013. Joint control of production, remanufacturing, and disposal activities in a hybrid manufacturing - remanufacturing system. European Journal of Operational Research, 231(2): 337-348. 
[15] Konstantaras I \& Papachristos S. 2007. Optimal policy and holding cost stability regions in a periodic review inventory system with manufacturing and remanufacturing options. European Journal of Operational Research, 178(2): 433-448.

[16] Kumar UD, Crocker J, Knezevic J \& El-Haram M. 2012. Reliability, maintenance and logistic support: A life cycle approach. Springer Science \& Business Media.

[17] Lalmazloumian M, Abdul-Kader W \& Ahmadi M. 2014. A Simulation Model of Economic Production and Remanufacturing System Under Uncertainty. In: Industrial and Systems Engineering Research. pp. 3211-3221.

[18] Lim LL, FlapPer SD \& GAYON JP. 2011. Optimal control of a hybrid production/remanufacturing system using one shared resource. In: ROADEF 2011. pp. 2-3. Saint-Etienne, France.

[19] LiU X, BAnerJee A \& Kim SL. 2009. Models for retail pricing and customer return incentive for remanufacturing a product. In: POMS 20th Annual Conference. pp. 1-30. Florida, USA.

[20] Mahadevan B, Pyke DF \& Fleischmann M. 2003. Periodic review, push inventory policies for remanufacturing. European Journal of Operational Research, 151(3): 536551.

[21] Marshall SE \& Archibald TW. 2015. Substitution in a hybrid remanufacturing system. In: 12th Global Conference on Sustainable Manufacturing, vol. 26. pp. 583-588. Elsevier.

[22] Nikoofal ME \& Moattar Husseini SM. 2010. An inventory model with dependent returns and disposal cost. International Journal of Industrial Engineering Computations, 1: 45-54.

[23] Polotski V, Kenne JP \& Gharbi A. 2015. Manufacturing-remanufacturing systems with setups. Journal of Manufacturing Systems, pp. 1-12.

[24] Raupp FMP, Angeli KD, Alzamora GGS \& Maculan N. 2015. MRP optimization model for a production system with remanufacturing. Pesquisa Operacional, 35(2): 311-328.

[25] ReimAnn M \& ZHANG W. 2013. Joint optimization of new production, warranty servicing strategy and secondary market supply under consumer returns. Pesquisa Operacional, 33(3): 325-342.

[26] Ross SM. 2010. Introduction to probability models (10th). Elsevier Inc.

[27] Sethi SP \& Thompson GL. 2000. Optimal Control Theory: Applications to Management Science and Economics. USA: Springer. 2nd ed. 
[28] Singh SR \& SAXENA N. 2012. An optimal returned policy for a reverse logistics inventory model with backorders. Advances in Decision Sciences, 2012: 1-21.

[29] TAhirov N, HaSAnOV P \& JABER MY. 2016. Optimization of closed-loop supply chain of multi-items with returned subassemblies. International Journal of Production Economics, 174: 1-10.

[30] TAI AH \& CHING WK. 2014. Optimal inventory policy for a Markovian two-echelon system with returns and lateral transshipment. International Journal of Production Economics, 151: 48-55.

[31] Turki S, Didukh S, Sauvey C \& RezG N. 2017. Optimization and analysis of a manufacturing-remanufacturing-transport-warehousing system within a closed-loop supply chain. Sustainability, 9(4): 561.

[32] Vercraene S, GAYON JP \& Flapper SD. 2014. Coordination of manufacturing, remanufacturing and returns acceptance in hybrid manufacturing/remanufacturing systems. International Journal of Production Economics, 148: 62-70. 